\title{
POTENCIAL HÍDRICO DO SUBSTRATO E TEOR DE ÁGUA DAS SEMENTES NA GERMINAÇÃO DO CRAMBE ${ }^{1}$
}

\author{
TATHIANA ELISA MASETTO², JOSUÉ DE BRITO QUADROS³, DÁGON MANOEL RIBEIRO³, \\ RODRIGO KELSON SILVA REZENDE ${ }^{4}$, SILVANA DE PAULA QUINTÃO SCALON ${ }^{4}$
}

\begin{abstract}
RESUMO - O estresse hídrico e o grau de umidade das sementes podem afetar as primeiras fases da germinação e prejudicar o pleno estabelecimento das culturas. Dessa forma, objetivou-se avaliar o efeito de potenciais hídricos do substrato e do teor de água das sementes na germinação do crambe e verificar a ocorrência de possíveis danos por embebição nas sementes. Os tratamentos foram constituídos de sementes de crambe, cultivar FMS Brilhante, com teores de água de 7,0, 12,8, 18,4 e $21,9 \%$ e submetidos aos seguintes potenciais hídricos no substrato, simulados com soluções aquosas de polietilenoglicol 6000 (PEG 6000): 0,0 (controle); -0,1; -0,2 e -0,4 MPa. As sementes foram semeadas sobre duas folhas de papel para germinação e posicionadas dentro de caixas de plástico do tipo "gerbox" e mantidas aos $25^{\circ} \mathrm{C}$. A qualidade fisiológica das sementes foi avaliada por meio da primeira contagem, porcentagem de germinação, comprimento de hipocótilo e de raiz primária, massa fresca e seca das plântulas. Utilizou-se o delineamento inteiramente casualizado, com quatro repetições de 50 sementes para cada tratamento, sendo os dados submetidos à análise de regressão. À medida que a disponibilidade hídrica do substrato diminuiu, houve redução na germinabilidade das sementes em todos os teores de água testados, especialmente em sementes com 7,0 e 12,8\% de teor de água, que apresentaram menos de $48 \%$ de plântulas normais sob - 0,4 MPa. Apesar da redução das características avaliadas com a deficiência hídrica, a extensão dos danos em sementes de crambe é determinada pelo teor de água das sementes e pela severidade do estresse hídrico.
\end{abstract}

Termos para indexação: Crambe abyssinica, polietilenoglicol, qualidade fisiológica.

\author{
EFFECT OF SUBSTRATE WATER AVAILABILITY AND SEED \\ MOISTURE CONTENT ON CRAMBE GERMINATION
}

\begin{abstract}
Water stress and seed water content can affect the first stages of germination and prejudice crop establishment. The objective of the present study was to evaluate the effect of substrate water availability and seed water content on crambe germination and to verify any harmful effects of seed imbibition. The treatments consisted of FMS Brilhante crambe seeds with $7.0 \%, 12.8 \%, 18.4 \%$ and $21.9 \%$ moisture content, submitted to substrate water availability of 0.0 (control); $-0.1 ;-0.2$ and $-0.4 \mathrm{MPa}$. Seeds were sown on two germination papers and placed inside plastic boxes at a constant $25^{\circ} \mathrm{C}$. Seed physiological quality was evaluated from the first count, percentage germination, hipocotyl and primary root lengths and seedling fresh and dry weights.
\end{abstract}

\footnotetext{
${ }^{1}$ Submetido em 17/06/2010. Aceito para publicação em 09/02/2011.

${ }^{2}$ Prof. Dra. Visitante da Universidade Federal da Grande Dourados (UFGD), Cidade Universitária, Caixa Postal 533, CEP: 79804-970, Dourados-MS - tathianamasetto@ufgd.edu.br
}

\footnotetext{
${ }^{3}$ Acadêmicos da UFGD, Dourados-MS - josue_quadros@agronomo.eng. br; dagonribeiro@hotmail.com.

${ }^{4}$ Prof. Dr. Adjunto da UFGD, Dourados-MS - rkelson@ufgd.edu.br; silvana.scalon@ufgd.edu.br.
} 
The experimental design was completely randomized with four replications of 50 seeds for each treatment. As substrate water availability decreased, the germinability was reduced for all seed moisture contents, especially for seeds with $7.0 \%$ and $12.8 \%$ moisture contents, resulting in less than $48 \%$ normal seedlings at $-0,4 \mathrm{MPa}$. Despite a reduction in the parameters due to water deficiency, the extension of the damage in crambe seeds is determined by the seed water content and the severity of the water stress.

Index terms: Crambe abyssinica, polyethylene glycol, physiological quality.

\section{INTRODUÇÃO}

O crambe (Crambe abyssinica - Brassicaceae) é uma espécie oleaginosa recomendada para a produção de biodiesel. Apresenta boas possibilidades de cultivo na região centro-sul de Mato Grosso do Sul, sendo também cultivada na região norte/nordeste do Paraná e sul de São Paulo, onde apresenta tolerância à seca, principalmente a partir do seu desenvolvimento vegetativo e a temperaturas amenas, comportando-se como cultura de outono/inverno (Pitol, 2008). A região centro-sul do estado de Mato Grosso do Sul possui um grande potencial para o estabelecimento de culturas destinadas à produção de biodiesel, dada à expressiva área agrícola ociosa no período de outonoinverno (Pitol, 2007). Além disso, a característica de rusticidade do crambe é uma premissa importante para a produção de sementes dessa cultura no estado.

Durante a estação de outono-inverno no estado de Mato Grosso do Sul a precipitação média é, em geral, inferior a $60 \mathrm{~mm}$ (Fundação MS, s.d.), sendo que a cultura do crambe encontra-se sob estresse hídrico durante a maior parte do tempo entre a semeadura e a colheita. De acordo com Donaldson (1996), a fisiologia das plantas varia consideravelmente sob estresse hídrico durante o desenvolvimento da cultura e as sementes devem ser capazes de absorver água e emergir em áreas com deficiência hídrica e alta temperatura. O estresse hídrico diminui a velocidade de emergência e de desenvolvimento da plântula, afetando a maioria dos componentes agronômicos, como número de folhas, sementes por planta, tamanho e peso de sementes.

Espécies que produzem sementes que germinam sob baixos potenciais hídricos têm a vantagem de estabelecimento em locais onde sementes sensíveis à seca não sobreviveriam (Tang et al., 2009). Sementes pequenas, particularmente produzidas por espécies de crescimento rápido, são capazes de tolerar ambientes mais secos pela plasticidade morfogenética e fisiológica do que sementes grandes, entretanto, plântulas formadas a partir de sementes maiores sobrevivem sob condições mais intensas de deficiência hídrica (Khurana e Singh, 2004). Durante a secagem, sementes pequenas secam mais rapidamente na população, consequentemente há uma relação linear significativa entre o teor de água da semente inteira e a massa da semente (Daws et al., 2004).

Durante a embebição, as sementes lixiviam solutos no meio de semeadura, e a lixiviação, que é geralmente breve, não causa danos severos ao eixo embrionário. Recentemente, estalixiviaçãotem sidoatribuídaaoaumento transitório da permeabilidade da membrana, associado com a presença de substâncias anfifílicas que estão no processo de síntese "de novo" no citoplasma durante a reidratação. A completa perda de viabilidade celular devido aos danos irreversíveis à membrana é chamada de dano por embebição e pode reduzir a germinação. Teores de água elevados das sementes e temperaturas amenas podem diminuir o estresse da reidratação das sementes (Neya et al., 2004). O transporte de água é o principal mecanismo de embebição pelas sementes para completar a germinação e consequentemente a emergência da plântula (Wuest, 2007).

Um dos produtos mais comumente utilizados para simular o estresse osmótico é o polietilenoglicol (PEG), um soluto quimicamente inerte e atóxico, que não é absorvido pelas sementes devido ao grande tamanho de suas moléculas (Villela et al., 1991). Diversos trabalhos relatam a importância da disponibilidade hídrica do substrato para favorecer o desenvolvimento da plântula de diversas culturas. Hosseini et al. (2009) observaram a redução do crescimento de plântulas de grão-de-bico; em sementes de sorgo o crescimento radicular foi mais sensível que a germinação sob condições de deficiência hídrica (Patanè et al., 2009) e em sementes de tomate com altos teores de água ( $35 \%$ - 37\%) não houve danos celulares 
pela rápida entrada de água, diferindo do observado em sementes com baixos teores de água (Badek at el., 2006).

As pesquisas com sementes de crambe ainda são incipientes na literatura e até o momento não foram encontrados relatos sobre possíveis efeitos do estresse hídrico em sementes dessa espécie. Diante disso, objetivouse com este trabalho avaliar o efeito de diferentes potenciais hídricos do substrato e de teores de água das sementes na germinação de crambe.

\section{MATERIAL E MÉTODOS}

A pesquisa foi conduzida no Laboratório de Sementes da Faculdade de Ciências Agrárias da Universidade Federal da Grande Dourados, Dourados, MS, com um lote de sementes de crambe (Crambe abyssinica HoeschtBrassicaceae), da cultivar FMS Brilhante, produzida em Mato Grosso do Sul, no ano de 2009.

Para avaliar o efeito do teor de água das sementes associado à disponibilidade hídrica do substrato, obtiveram-se sementes com diferentes teores de água, adotando-se o procedimento de umedecimento artificial da seguinte forma: foram empregadas caixas de plástico do tipo "gerbox", contendo $40 \mathrm{~mL}$ de água destilada no fundo e telas de alumínio em cada uma das caixas, com cerca de 240 sementes distribuídas sobre as telas. As caixas foram tampadas e levadas para câmaras do tipo B.O.D. sob temperatura de $25^{\circ} \mathrm{C}$. Durante a permanência das caixas na câmara foi realizado, periodicamente, o monitoramento da massa úmida das sementes em hidratação, por meio de pesagens, adotando-se como referência o teor de água inicial das sementes até serem atingidos os teores de água desejados de 7,0\% (teor de água inicial); $12,8 \%, 18,4 \%$ e $21,9 \%$, correspondentes às sementes que permaneceram durante 6,12 e 24 horas de hidratação, respectivamente. O teor de água das sementes foi determinado com quatro repetições pelo método da estufa a $105^{\circ} \pm 3^{\circ} \mathrm{C}$, por 24 horas, conforme Brasil (2009) e os resultados foram expressos com base na massa das sementes úmidas.

Amostras de sementes pertencentes aos quatro teores de água foram submetidas a germinação sob diferentes potenciais hídricos. Para o umedecimento do papel, usado como substrato no teste de germinação, foram utilizadas soluções aquosas de polietilenoglicol (PEG 6000), com potenciais de -0,1, -0,2 e -0,4 MPa, cuja quantidade de PEG 6000 foi calculada a partir da equação proposta por Michel e Kaufmann (1973), ou seja: $\psi$ os $=-(1,18 \times 10-2) \mathrm{C}-(1,18 \times 10-4) \mathrm{C} 2+(2,67$ $\mathrm{x} 10-4) \mathrm{CT}+(8,39 \times 10-7) \mathrm{C} 2 \mathrm{~T}$ em que: $\psi$ os $=$ potencial osmótico (bar); $\mathrm{C}=$ concentração (gramas de PEG 6000/ $\mathrm{Kg}$ de água destilada) e $\mathrm{T}=$ temperatura $\left({ }^{\circ} \mathrm{C}\right)$, a qual foi considerada a de $25{ }^{\circ} \mathrm{C}$.

Dessa forma, para a obtenção de potenciais hídricos de $-0,1,-0,2$ e -0,4 $\mathrm{MPa}$, as soluções aquosas foram compostas, respectivamente, de 78,49,119,54 e 178,34 $\mathrm{g}$ de PEG 6000 por quilograma de água destilada. Para o preparo dessas soluções, inicialmente fez-se a pesagem da quantidade de PEG 6000 necessária. Após, o PEG 6000 foi misturado com água destilada até a sua total dissolução. Feito isso, as sementes apresentando os quatro teores de água citados anteriormente $(7,0 \%, 12,8 \%, 18,3 \%$ e $21,9 \%$ ), foram colocadas para germinar sobre papel umedecido com as soluções de PEG 6000 em diferentes concentrações, resultando nas quatro disponibilidades hídricas desejadas.

As sementes foram avaliadas pelos seguintes testes: primeira contagem de germinação - realizada com o teste de germinação de acordo com as recomendações de Brasil (2009) com quatro repetições de 50 sementes, consistindo no registro das porcentagens de plântulas normais no quarto dia após a semeadura; germinação - avaliada no sétimo dia após a semeadura, por ocasião do encerramento do experimento, considerando-se germinadas as sementes que emitiram plântulas normais. Os resultados foram expressos em porcentagem média com base no número de plântulas normais (Brasil, 2009); comprimento de hipocótilo - no momento da última contagem, mediuse o comprimento do hipocótilo das plântulas com régua graduada em mm e os resultados foram expressos em $\mathrm{cm}$. plântula ${ }^{-1}$; comprimento da raiz primária - determinado na última contagem do teste de germinação, nas plântulas normais de cada repetição, com o auxílio de régua graduada em $\mathrm{mm}$ e os resultados foram expressos em $\mathrm{cm}$. plântula ${ }^{-1}$; massa fresca total de plântula - obtida gravimetricamente nas mesmas plântulas utilizadas para aferir os comprimentos do hipocótilo e das raízes; massa seca total de plântula - depois de obtida a massa fresca das plântulas o material vegetal foi levado à estufa e seco a $70 \pm 2{ }^{\circ} \mathrm{C}$ até atingir massa constante, sendo determinada gravimetricamente. $\mathrm{O}$ valor das massas fresca e seca das plântulas foi dividido pelo número de plântulas normais e os resultados expressos em mg.plântula ${ }^{-1}$.

O delineamento experimental foi o inteiramente casualizado em esquema fatorial $4 \times 4$ (quatro teores de água e quatro potenciais hídricos do substrato), com 
quatro repetições. Os dados foram submetidos à análise de regressão para o estudo dos efeitos dos diferentes níveis de disponibilidade hídrica, para cada teor de água das sementes, utilizando o programa estatístico SISVAR (Ferreira, 2000).

\section{RESULTADOS E DISCUSSÃO}

No potencial hídrico de $0,0 \mathrm{MPa}$ a germinação observada na primeira contagem foi superior a $60 \%$ de plântulas normais (Figura 1); as sementes com 12,8\% e $18,3 \%$ apresentaram $70,5 \%$ e $76,0 \%$ de plântulas normais na primeira contagem, respectivamente, em comparação aos 62 e $63 \%$ observados para sementes com 7 e $21,9 \%$ de teor de água. Independentemente do teor de água das sementes, foi observada uma redução crescente na formação de plântulas normais na primeira contagem na medida em que a disponibilidade hídrica do substrato foi reduzida (Figura 1). Sementes com o menor teor de água $(7,0 \%)$ foram mais sensíveis à redução do potencial hídrico, até aproximadamente $-0,3$ $\mathrm{MPa}$, e apresentaram resultados médios de germinação inferiores em relação às sementes com maiores teores de água no substrato.

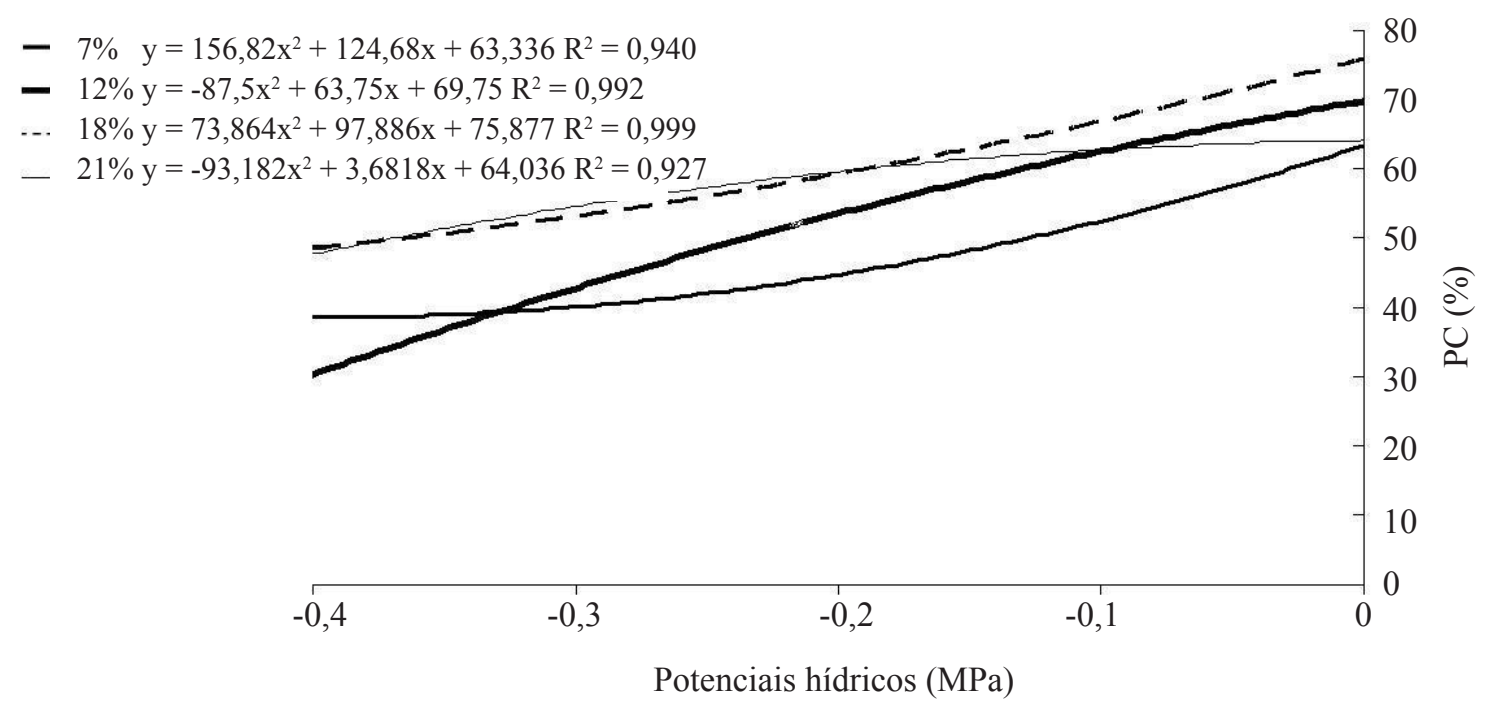

FIGURA 1. Primeira contagem (PC) de germinação de sementes de crambe com diferentes teores de água sob quatro condições de potenciais hídricos.

Resultados semelhantes foram encontrados por Mortele et al. (2006), que observaram redução no desempenho das sementes de milho-pipoca com a diminuição do potencial osmótico do substrato. Forti et al. (2009) não observaram diferenças na germinação das sementes de feijão com diferentes teores de água em diversas disponibilidades hídricas, nem mesmo no menor potencial hídrico estudado de -0,4 MPa e teor de água da semente de $9 \%$.

$O$ aumento da deficiência hídrica através do incremento nas concentrações de PEG 6000 na solução do substrato foi responsável por decréscimos significativos na porcentagem final de germinação de sementes de crambe com os menores teores de água estudados (Figura
2). Possivelmente, as sementes com $7,0 \%$ e $12,8 \%$ foram mais sensíveis ao estresse hídrico que as sementes com teores de água acima de $18 \%$ quando submetidas aos níveis mais drásticos de restrição hídrica $(-0,2$ e $-0,4$ $\mathrm{MPa}$ ) (Figura 2). Mesmo sob potencial de 0,0 $\mathrm{MPa}$, as sementes com $7,0 \%$ e $12,8 \%$ germinaram menos $(64,5 \%$ e $71,0 \%$, respectivamente) do que as sementes com teores de água mais elevados, que apresentaram mais de $75 \%$ de germinação. De acordo com os resultados, a germinação das sementes foi mais influenciada pelo teor de água das sementes do que pela disponibilidade hídrica do substrato. Oliveira e Gomes-Filho (2009) relataram que em sementes de sorgo forrageiro a redução do potencial osmótico da solução do substrato também influenciou 
a germinação tornando-a mais lenta. Esse fato pode ser explicado pela necessidade de que haja um nível de hidratação adequado durante a fase de embebição das sementes, de modo que este venha a permitir a reativação dos processos metabólicos, culminando no crescimento do eixo embrionário (Marcos Filho, 2005).

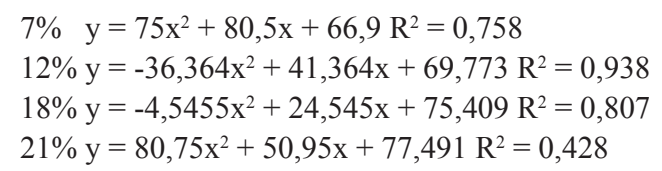

$-0,2$

$-0,1$

0

Potenciais hídricos $(\mathrm{MPa})$

\section{FIGURA 2. Germinação (G) de sementes de crambe com diferentes teores de água sob quatro condições de potenciais hídricos.}

No presente trabalho, sementes de crambe com teores de água de 7,0\% e 12,8\% foram mais sensíveis à redução contínua da disponibilidade hídrica dos substratos na germinação em relação às sementes com teores de água acima de $18 \%$. O estresse hídrico pode reduzir tanto a porcentagem quanto a velocidade de germinação, com uma grande variação de respostas entre as espécies, desde aquelas muito sensíveis, até as mais resistentes. Dessa forma, sementes de espécies resistentes possuem a vantagem ecológica de estabelecer plântulas em áreas onde sementes sensíveis à seca não podem fazê-lo (Bewley e Black, 1994).

Taiz e Zeiger (2004) relatam que o primeiro efeito mensurável do estresse hídrico é a diminuição no crescimento, causada pela redução da expansão celular. O comprimento de hipocótilo das plântulas de crambe (Figura 3) obtidas a partir de sementes com diferentes teores de água foi mais sensível do que o comprimento de raiz primária nas concentrações osmóticas do substrato, embora pela análise desta variável tenha sido verificado que também houve a redução gradativa do comprimento de raiz das plântulas com a restrição hídrica (Figura 4). O estresse hídrico reduz a habilidade de embebição de água, o que provoca rapidamente a redução no crescimento, além de um conjunto de mudanças metabólicas que culminam com diminuição do crescimento da parte aérea, provavelmente devido aos hormônios produzidos pelas raízes (Munns, 2002).

A habilidade para desenvolver raízes varia amplamente entre as espécies e pode estar relacionada à hipótese de adaptação, devido a proliferação de raízes aumentar a absorção de nutrientes numa situação de competição; ou pode estar relacionada com a taxa de crescimento de uma determinada planta (Kembel et al., 2008). Muitas proteínas que são induzidas nos estágios iniciais do estresse hídrico são também envolvidas na morfogênese da raiz e no metabolismo de carbono/nitrogênio, as quais podem contribuir para a anulação do estresse por meio do aumento do crescimento radicular (Yoshimura et al., 2008). No caso do crambe, a literatura relata que trata-se de uma planta adaptada a condições inóspitas (Pitol, 2007) e tal rusticidade pode favorecer a tolerância das sementes sob diversas condições.

Os resultados médios de massa fresca das plântulas de crambe foram superiores em sementes com teores de água acima de $18 \%$ e que não foram submetidas à redução da disponibilidade hídrica do substrato (Figura 5). Com a redução do potencial hídrico do 
substrato para $-0,2 \mathrm{MPa}$ e $-0,4 \mathrm{MPa}$ foi detectada a diminuição na massa fresca das plântulas formadas, independentemente do teor de água das sementes, mas de forma mais acentuada nas sementes com maiores teores de água (Figura 5). Esta redução na biomassa, assim como no crescimento das plântulas, pode ser explicada pela diminuição no metabolismo das sementes, em função da menor disponibilidade de água para digestão das reservas e translocação de produtos metabolizados (Bewley e Black, 1994).

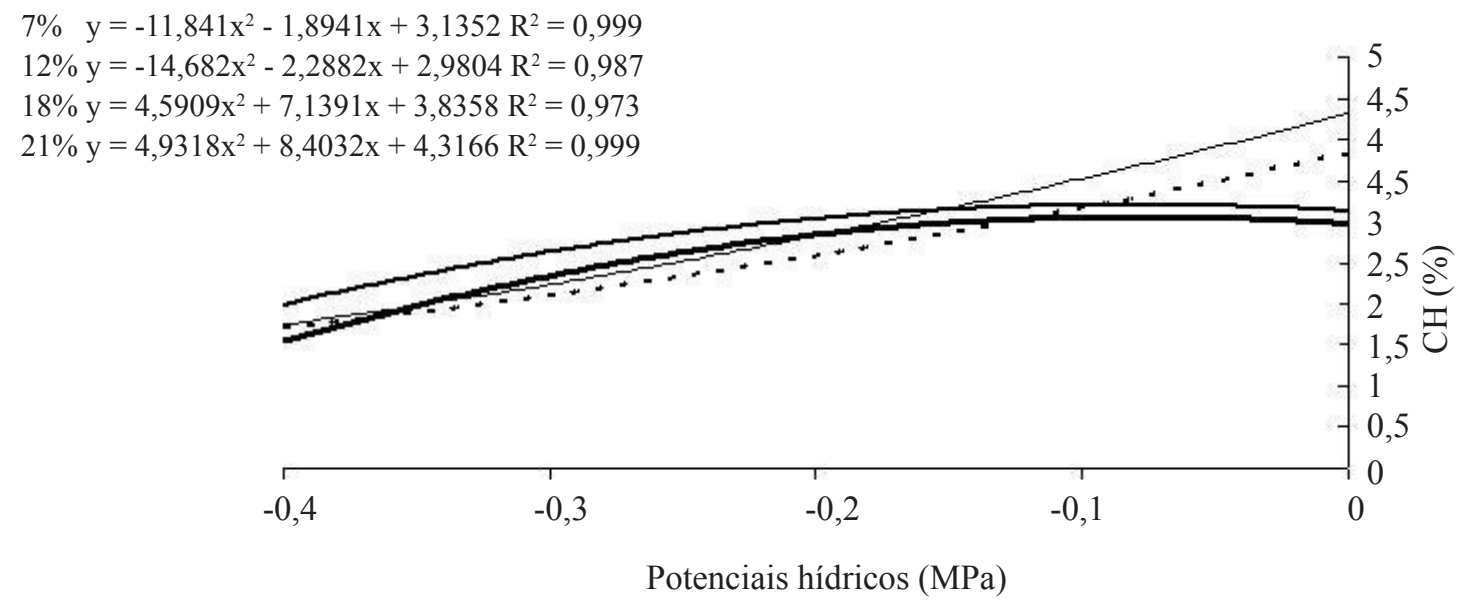

FIGURA 3. Comprimento de hipocótilo $(\mathrm{CH})$ de plântulas de crambe obtidas de sementes com diferentes teores de água sob quatro condições de potenciais hídricos.

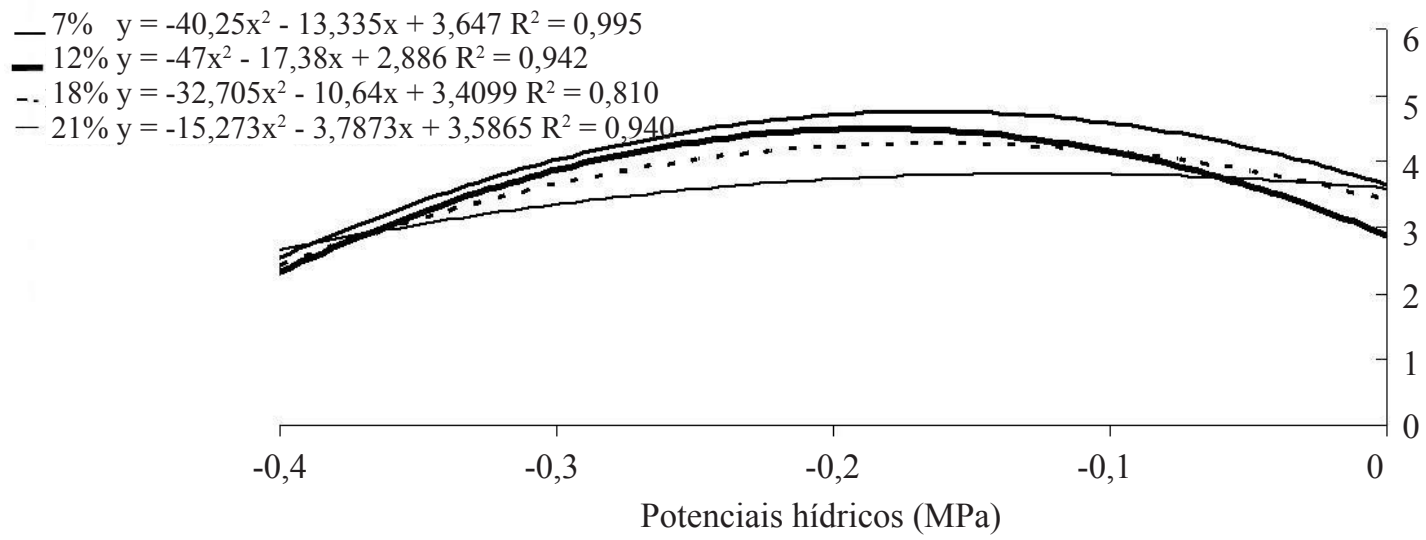

FIGURA 4. Comprimento de raiz primária (CR) de plântulas de crambe obtidas de sementes com diferentes teores de água sob quatro condições de potenciais hídricos. 


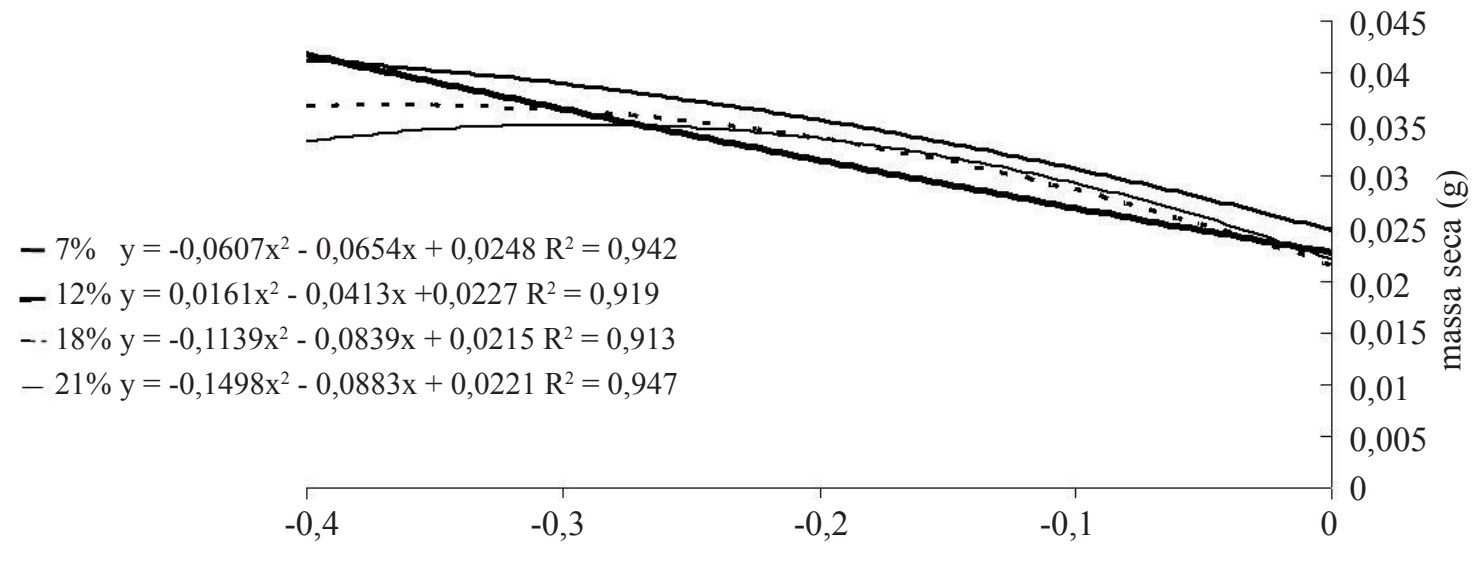

Disponibilidade hídrica

FIGURA 5. Massa fresca de plântulas de crambe obtidas de sementes com diferentes teores de água sob quatro condições de potenciais hídricos.

Houve um aumento na massa seca das plântulas em condições de estresse hídrico (potenciais abaixo de - 0,2 MPa) (Figura 6). Independentemente do teor de água das sementes, as plântulas originadas apresentaram um incremento na massa seca, embora a restrição hídrica do substrato fosse acentuada, o que provavelmente pode ser explicado pelo enrijecimento da parede de células em desenvolvimento como mecanismo primário de ajuste à redução da disponibilidade de água para embebição.

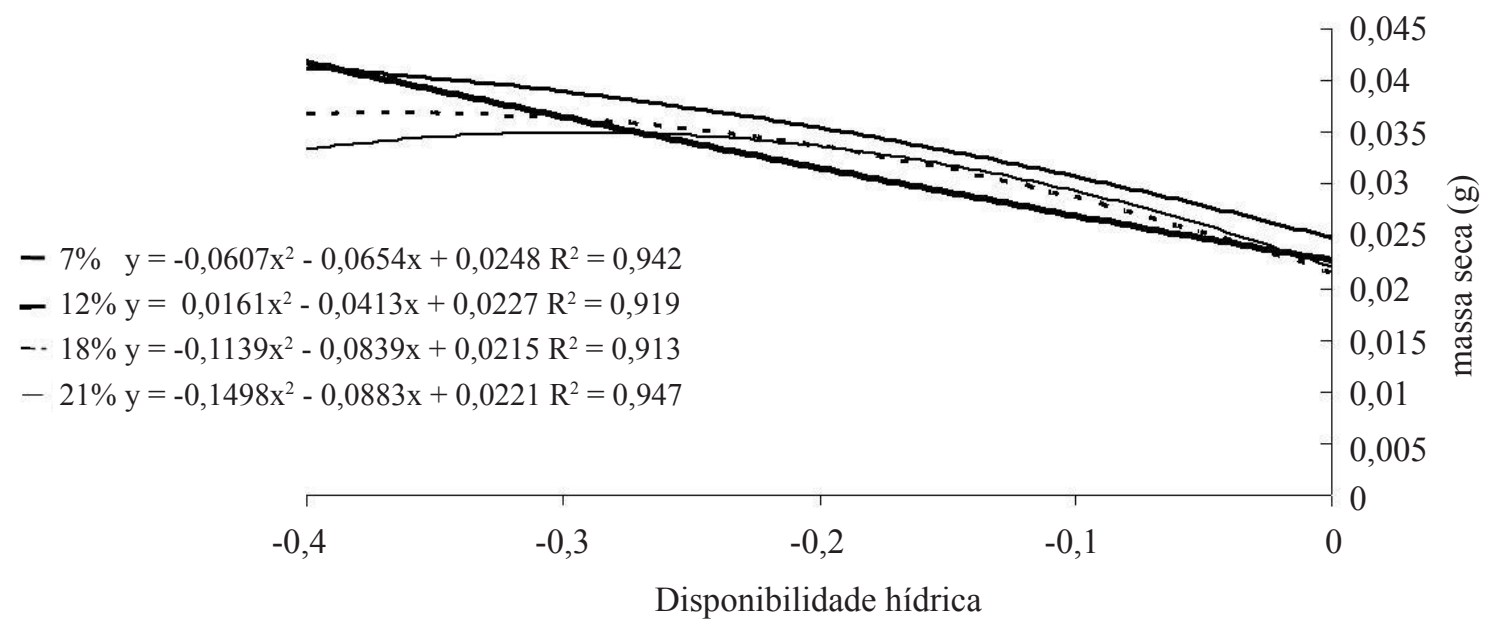

FIGURA 6. Massa seca de plântulas de crambe obtidas de sementes com diferentes teores de água sob quatro condições de potenciais hídricos.

Assim como Mortele et al. (2008) sugeriram o uso de soluções de polietilenoglicol em análises de rotina de germinação como alternativa para se estimar o vigor das sementes de milho-pipoca sob estresse hídrico, diante dos resultados obtidos na presente pesquisa, o estresse simulado com o PEG 6000, em laboratório, também 
poderia ser útil na avaliação da qualidade fisiológica de sementes de crambe que são produzidas em Mato Grosso do Sul e que são destinadas às áreas propensas à estiagem.

\section{CONCLUSÕES}

À medida que a disponibilidade hídrica do substrato diminui, há redução na germinação das sementes independentemente do teor de água, porém de forma mais evidente em sementes com 7,0 e 12,8\% de teor de água.

Apesar da redução na germinação, no comprimento de hipocótilo e de raiz e na massa fresca das plântulas com a deficiência hídrica, especialmente em sementes com teores de água abaixo de $18 \%$, as sementes de crambe são tolerantes as condições de estresse hídrico testadas.

\section{REFERÊNCIAS}

BADEK, B.; DUIJN, B.; GRZESIK, M. Effects of water supply methods and seed moisture content on germination of China aster (Callistephus chinensis) and tomato (Lycopersicon esculentun Mill.) seeds. European Journal of Agronomy, v.24, p.45-51, 2006.

BEWLEY, J.D.; BLACK, M. Seeds: physiology of development and germination. 2.ed. New York: Plenum Press, 1994. 445p.

BRASIL. Ministério da Agricultura, Pecuária e Abastecimento. Regras para análise de sementes. Ministério da Agricultura, Pecuária e Abastecimento. Secretaria de Defesa Agropecuária. Brasília: MAPA/ACS, 2009. 395p. http://www.agricultura.gov.br/images/MAPA/ arquivos_portal/Regras_Analise\%20_Sementes.pdf

DAWS, M.I.; GAMÉNÉ, C.S.; GLIDEWELL, S.M.; PRITCHARD, H.W. Seed Science Research, v.14, p.185195, 2004. doi: 10.1079/SSR2004168. http://journals. cambridge.org/action/displayFulltext?type $=1 \&$ fid $=709660$ \&jid=SSR\&volumeId=14\&issueId=02\&aid=709648\&bod yId=\&membershipNumber $=\&$ societyETOCSession $=$

DONALDSON, E. Crop traits for water stress tolerance. American Journal of Alternative Agriculture, v.11, p.89-94, 1996. doi: 10.1017/S0889189300006846. http:// journals.cambridge.org/action/displayAbstract?fromPage $=$ online\&aid $=6362504$

FERREIRA, D.F. SISVAR. Sistema para análise de variância. Lavras: UFL/DEX, 2000, CD-ROM.

FORTI, V.A.; CICERO, S.M.; PINTO, T.L.F. Efeitos de potenciais hídricos do substrato e teores de água das sementes na germinação de feijão. Revista Brasileira de Sementes, v.31, n.2, p.63-70, 2009. http://www.scielo.br/ $p d f / r b s / v 3 \ln 2 / v 3 \ln 2 a 07 . p d f$.

FUNDAÇÃO MS. Disponível em <http://www. fundacaoms.org.br/contact.php $>$. Acesso em: 11 jun. $\underline{2010 .}$

HOSSEINI, N.M.; PALTA, J.A.; BERGER, J.D.; SIDDIQUE, J.H.M. Sowing soil water content effects on chickpea (Cicer arietinum L.): seedling emergence and early growth interaction with genotype and seed size. Agricultural Water Management, v.96, p.1732-1736, 2009.

KEMBEL,S.W.;KROON,H.; CAHILL Jr,J.F.;MOMMER, L. Improving the scale and precision of hypotheses to explain root foraging ability. Annals of Botany, v.101, p.1295-1301, 2008. doi:10.1093/aob/mcn044. http://aob. oxfordjournals.org/content/101/9/1295.full $>$

KHURANA, E.; SINGH, J.S. Germination and seedling growth of five tree species from tropical dry forest in relation to water stress: impact of seed size. Journal of Tropical Ecology, v.20, p.385-396, 2004. doi: 10.1017/ S026646740400135X.http://journals.cambridge.org/action/ displayFulltext?type $=1 \&$ fid $=232466 \&$ jid $=$ TRO \&volumeId $=20 \&$ issueId $=04 \&$ aid $=232465 \&$ bodyId $=\&$ membershipNu $\underline{\text { mber }=\& \text { societyETOCSession }=}$

MARCOS FILHO, J. Fisiologia de sementes de plantas cultivadas. Piracicaba: FEALQ, 2005. 495p.

MICHEL, B.E.; KAUFMANN, M.R. The osmotic potential of poliethylene glycol 6000. Plant Physiology, Bethesda. v.51, p.914-916. 1973. http://www.plantphysiol. org/cgi/reprint/51/5/914

MORTELE, L.M.; LOPES, P.C.; BRACCINI, A.L.; SCAPIM, C.A. Germinação de sementes e crescimento de plântulas de cultivares de milho-pipoca submetidas ao estresse hídrico e salino. Revista Brasileira de Sementes, v.28, n.3, p.169-176, 2006. http://www.scielo.br/pdf/rbs/ v28n3/24.pdf

MORTELE, L.M.; SCAPIM, C.A.; BRACCINI, A.L.; RODOVALHO, M.A.; BARRETO, R.R. Influência do estresse hídrico sobre o desempenho fisiológico de sementes de híbridos simples de milho-pipoca. Ciência e Agrotecnologia, v.32, n.6, p. 1810-1817, 2008. doi: 10.1590/S1413-70542008000600020. http://www.scielo. br/pdf/cagro/v32n6/v32n6a20.pdf

MUNNS, R. Comparative physiology of salt and water stress. Plant, Cell and Environment, v25, p.239- 
250, 2002. http://www.soilzone.com/Library/Salinity/ Comparative\%20physiology $\% 20$ of $\% 20$ salt $\% 20$ and $\% 20$ water $\% 20$ stress.pdf

NEYA, O.; GOLOVINA, E.A.; NIJSSE, J. HOEKSTRA, F.A. Ageing increases the sensitivity of neem (Azadirachta indica) seeds to imbibitional stress. Seed Science Research, v.14, p.205-217, 2004. doi: 10.1079/SSR2004170. http:// journals.cambridge.org/action/displayFulltext?type $=6 \&$ fid $=709684 \&$ jid $=$ SSR \&volumeId=14\&issueId $=02 \&$ aid $=709$ 680\&bodyId=\&membershipNumber $=$ \&societyETOCSess $\underline{\text { ion }=\& \text { fulltextType }=\text { RA\&fileId }=\text { S0960258504000212 }}$

OLIVEIRA, A.B.; GOMES-FILHO, E. Germinação e vigor de sementes de sorgo forrageiro sob estresse hídrico e salino. Revista Brasileira de Sementes, v.31, n.3, p.48-56, 2009. http://www. scielo.br/scielo.php?script $=$ sci_arttext\&pid $=\mathrm{S} 0101$ $\underline{31222009000300005 \& \operatorname{lng}=\text { en } \& n r m=\text { iso }}$

PATANE, C.; CAVALlARO, V.; COSENTINO, S.L. Germination and radicle growth in unprimed and primed seeds of sweet sorghum as affected by reduced water potential in $\mathrm{NaCl}$ at different temperatures. Industrial Crops and Products, v.30, p.1-8, 2009.

PITOL, C. Biodiesel: culturas, sistemas de produção e rotação de culturas. In: Tecnologia e produção - culturas: safrinha e inverno 2007. http://www.fundacaoms.org.br/ page.php?21

PITOL, C. Cultura do crambe. In: Tecnologia e Produção: milho safrinha e culturas de inverno. Fundação MS, p.85-
$88,2008$.

TANG, A.; TIAN, M.; LONG, C. Seed dormancy and germination of three herbaceous perennial desert ephemerals from the Junggar Basin, China. Seed Science Research, v.19, p.183-189, 2009. doi:10.1017/ S096025850999002X. http://journals.cambridge.org/action/ displayFulltext?type $=6 \&$ fid $=5995588 \& \mathrm{jid}=\mathrm{SSR} \&$ volumeI $\mathrm{d}=19 \&$ issueId $=03 \&$ aid $=5995584 \&$ body $I d=\&$ membership Number $=\&$ societyETOCSession $=\&$ fulltextType $=$ RA\&file $\underline{\mathrm{Id}=\mathrm{S} 096025850999002 \mathrm{X}}$

TAIZ, L.; ZEIGER, E. Fisiologia vegetal. 3.ed. Porto Alegre: Artmed, 2004. 719p.

VILLELA, F.A.; DONI FILHO, L.; SIQUEIRA, E.L. Tabela do potencial osmótico em função da concentração de polietileno glicol 6000 e da temperatura. Pesquisa Agropecuária Brasileira, v.26, p.1957-1968, 1991.

WUEST, S. Vapour is the principal source of water imbibed by seeds in unsaturated soils. Seed Science Research, v.17, p.3-9, 2007. doi: 10.1017/S0960258507383165. http:// journals.cambridge.org/action/displayFulltext?type $=6 \&$ fid $=942252 \&$ jid $=$ SSR \& volumeId $=17$ \&issue $I d=01 \&$ aid $=942$ 248\&bodyId=\&membershipNumber $=\&$ societyETOCSess ion $=\&$ fulltextType $=$ RA\&fileId $=$ S0960258507383165

YOSHIMURA, K.; MASUDA, A.; KUWANO, M.; YOKOTA, A. AKASHI, K. Programmed proteome response for drought avoidance/tolerance in the root of a $\mathrm{C}_{3}$ xerophyte (wild watermelon) under water deficits. Plant Cell Physiology, v.49, n.2, p.226-241, 2008.http://pcp. oxfordjournals.org/content/49/2/226.full 